\title{
CORRIGENDUM
}

\section{Effect of magnesium supplementation on glucose metabolism in people with or at risk of diabetes: a systematic review and meta-analysis of double-blind randomized controlled trials}

N Veronese, S Watutantrige-Fernando, C Luchini, M Solmi, G Sartore, G Sergi, E Manzato, M Barbagallo, S Maggi and B Stubbs

European Journal of Clinical Nutrition (2016) 70, 1463; doi:10.1038/ejcn.2016.209

Correction to: European Journal of Clinical Nutrition (2016) 70, 1354-1359; doi:10.1038/ejcn.2016.154; published online 17 August 2016

Since the publication of this article, the authors have noticed that the author name 'S Watutantrige-Fernando' was displayed incorrectly. The PDF and the online versions have been amended. 